\title{
On French on Theories and Representation
}

\author{
Sebastian Lutz \\ Department of Philosophy \\ Uppsala University \\ sebastian.lutz@gmx.net \\ Preprint: 2021-01-05
}

Contribution to a symposium on Steven French. 2020. There Are No Such Things as Theories. Oxford: Oxford University Press.

Metascience, 2021. DOI: 10.1007/s11016-021-00612-9.

\begin{abstract}
In his refreshingly non-parochial book There Are No Such Things as Theories, Steven French develops an ontology and an account of representation for the Partial Structures View in the philosophy of science as a competitor to the logical empiricists' Received View. I argue that formally and practically, the two views are on a par, and that French just needs to take a few more steps with his ontology and account of representation to arrive at the logical empiricists' positions.
\end{abstract}

\section{From set theory and partial structures to predicate logic}

The story of the Semantic View is one of rapprochement. Using set or model theory for the formalization of theories and their relations to experiments, the Semantic View was to have greater expressive strength while being less dependent on language than the Syntactic View, which uses formalizations in predicate logic. But the alleged greater language independence of the Semantic View turned out to be nothing of the sort (Halvorson 2013; Lutz 2014, $\mathbb{S} 3$ ), and the two views turned out to be intertranslatable (da Costa and Chuaqui 1988; Hudetz 2017).

The Partial Structures View was developed French and others as a generalization of the model theoretic variant of the Semantic View and as a more powerful competitor to the Syntactic View, and specifically its logical empiricist variant, the Received View (French and Ladyman 1999). Again, intertranslatability proofs followed: Partial structures are expressible as sets of set-theoretic structures (Lutz 
$\left.2019, \$_{3}\right)$ and hence also syntactically, and they can even be expressed in the formalism of the Received View (Lutz 2015, \$5). Formally, then, nothing stands in the way of an alliance of the Partial Structures View and the Received View.

French (10) notes that type theory, the predicate logic most often assumed in the Received View, "can capture (much of) the kinds of mathematics we find in science", but goes on to claim that "it is for the aforementioned reason of impracticality, at least partly, that we don't generally come across this kind of formalization in scientific practice itself" (11). This is no reason for preferring axiomatic set theory over type theory, however, since "those familiar with both type theory and axiomatic set theory recognize that in some ways the former provides a more natural vehicle than the latter for formalizing what mathematicians actually do" (Andrews 2002, xii). Accordingly, we don't generally come across set-theoretic axiomatizations in scientific practice itself, either. The reason is probably one of which French (cf. Ch. 9) is keenly aware: The goals of scientists (including mathematicians) are different from those of logicians and philosophers of science. As Mermin (1993, 804) puts it regarding physicists, they are "simply less willing than philosophers to suffer through a few pages of dreary analysis to prove something they never doubted in the first place". Practically, then, nothing stands in the way of an alliance of the Partial Structures View and the Received View, either.

French (43) himself concludes that in the competition between the Syntactic and the Semantic View (specifically the Partial Structures View), we have reached "the point where differences that previously seemed stark, no longer appear so". But he maintains that "the latter offers a more straightforward 'handle' on such relations as are claimed to hold when it comes to representation. In my opinion, there are certain pragmatic advantages that accrue at the level of the philosophy of science from adopting the structuralist framework" (70). Accordingly, in his wide-ranging and wonderfully non-parochial There Are No Such Things as Theories, French uses the Partial Structures View for developing an account of representation and a new ontology (or rather the eponymous non-ontology) for theories.

In the remainder of this contribution, I want to celebrate French's first steps towards a rapprochement between the Received and the Partial Structures View, and argue for the practicality of the Received View. I also want to show that French's views on ontology and representation have developed towards the logical empiricists' views as well, and I want to prod him further along on this way.

\section{On how we represent the world}

Some of the perceived impracticalities of using predicate logic for representing the world (or theories, if one assumes that they exist) stem from a problematic assumption about the relation of predicate logic, set theory, and the world. For instance, French (47) follows Thomson-Jones (2006) in claiming that a syntactic description only provides us with

'a perfectly good tool for picking out a collection of mathematical 


$\underset{\Sigma}{\text { sentences }} \stackrel{\text { formal }}{\text { interpretation }} \begin{gathered}\text { set-theoretic } \\ \text { structures } \mathbb{S}\end{gathered} \longrightarrow \begin{gathered}\text { morphism } \\ \text { set theoretic } \\ \text { world }\end{gathered}$

Figure 1: One way in which representations do not work.

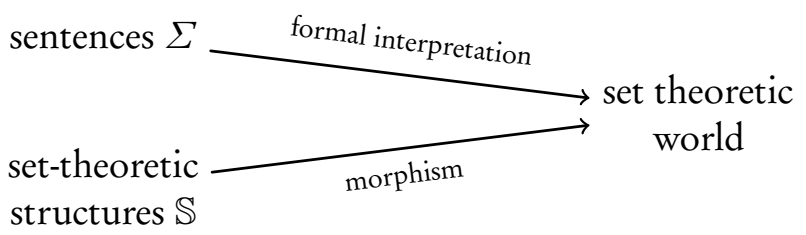

Figure 2: Another way in which representations do not work.

models' (ibid., p. 532). And the representational character of the latter is precisely what the advocates of the Semantic Approach need to focus on if they are to maintain the aversion to all the linguistic issues besetting the Syntactic view and stay close to scientific practice (ibid., pp. 533-4).

So the syntactic description is formally interpreted by a mathematical model, i.e., a set-theoretic structure, which in turn represents the set-theoretic world (figure 1). The intertranslatability proofs listed above also suggest this picture, because they usually consist solely of proofs that set theoretic structures can be determined up to isomorphism by sentences of predicate logic. But these proofs leave out the inverse direction because it is obvious: Descriptions in predicate logic are determined up to logical equivalence by their set theoretic models (cf. Lutz $2014, \$ 2$ ). So French and Thomson-Jones could just as well speak of set theory providing a perfectly good tool for picking out a collection of mathematical models (given in type theory).

Another problematic but slightly more realistic assumption, suggested by the term 'Semantic View', is that both predicate logic and set theory describe a settheoretic world (figure 2). But this confuses a model with the real thing: It happens to be that, when modeling the relation of predicate language and the world, the world is often modeled in a set theoretic meta-language, and the relation is modeled as a formal interpretation. When modeling the relation of set theory and the world, the world is often modeled in a set theoretic meta-language as well, and the relation is modeled as a morphism. Unsurprisingly, this connection seems much easier, even though it is just an artifact of the choice of the language in which the world is modeled (cf. Sarkar 1992, $\mathbb{S}$ \$12-13). But even when stacking the deck in favor of set theory like this, set theory provides no advantage over predicate logic in questions of representation (Lutz 2014, $\$ 4$ ).

Both formal interpretations and morphisms are only very impoverished models of the actual relation between language and the (non-set-theoretic) world with 


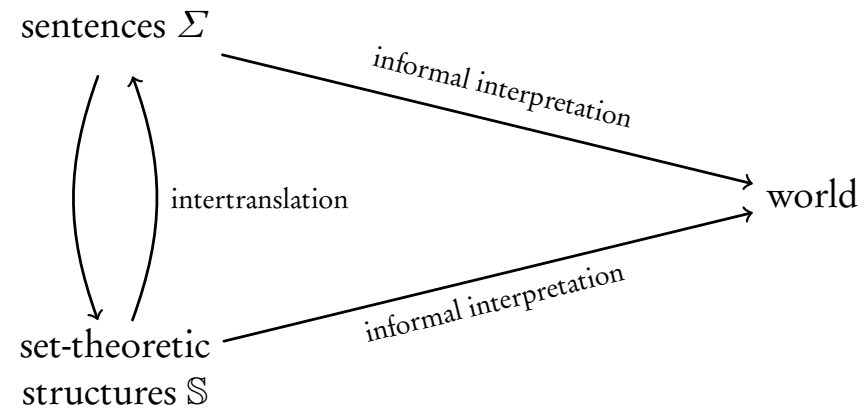

Figure 3: How representations work.

all its vaguenesses and vagaries, which is analyzed in the philosophy of language. And both predicate logic and set theory are just two different languages for describing the world (figure 3), with essentially the same troubles.

French (71-72) suggests an immersion-inference-interpretation account of how structures (which may describe theories or appearances) relate to the world. In the immersion stage, a mapping (explicated as a partial isomorphism) is established between the empirical set-up of the target system (which thus must be described by a partial structure) and the representational structure (which thus must be partial as well). In the inferential stage, consequences are drawn using the representational structure, and in the interpretational stage, these consequences are mapped (e. g. by a partial isomorphism) back to the target system. This mapping can be different from the one in the immersion stage.

This account is a formal model (figure 2) of how partial models represent the world that stacks the deck in favor of the Partial Structures View. Still, as an anonymous reader suggested, "there is nothing to stop the Syntactic Approach from accommodating these [...] aspects". French $(72$, n. 37) responds that then it is "up to an advocate of that approach to go ahead and do it!" Indeed: Since partially isomorphic partial structures are partial models of the same sentences, i.e., the same sentences are partially true in each (Bueno 2000, 279-280; Lutz 2019, claim 6), one can ignore the representational structure and just describe the partial structure $T$ of the target system in predicate logic. This can be done by describing the set of the $T$-normal structures, which are model-theoretic structures and thus can be described by a set $\Sigma$ of sentences (or set thereof) in type theory. If one wants to remain in a first order language (since partial structures are first order structures), one can describe the partial structure by its diagram $\mathscr{D}(T)$ (Mikenberg, da Costa, and Chuaqui 1986, definition 6). French does not describe in detail how to draw inferences from the partial representational structure $R$, but it seems reasonable that the inferences consist in determining which claims are partially true in the partial structure, or which structures are $R$-normal. The $R$-normal structures are (up to isomorphism) the models of $\Sigma$. The sentences 
partially true in $R$ are those first-order sentences $\varphi$ in the vocabulary of $T$ that are compatible with $\Sigma$, since these are true in a model of $\Sigma$ and thus in an $R$ normal structure. Mikenberg, da Costa, and Chuaqui (1986, corollary 11) show that these are also the sentences compatible with $\mathscr{D}(T)$. In the interpretation stage, each of the inferred sentences $\varphi$ restricts the possible partial structures to those in which $\varphi$ is partially true, and each inferred $R$-normal structure restricts the possible partial structures to those which are partially isomorphic to a partial structure $S$ for which the inferred $R$-normal structure is $S$-normal. The partial isomorphism for the $R$-normal structures is necessary because French allows for different mappings in the immersion and interpretation stages. For sentences $\varphi$, no such detour is necessary because they do not distinguish between partially isomorphic structures.

This accommodation of the immersion-inference-interpretation account in the Syntactic View may seem baroque, but only because it includes a sketch of an equivalence proof. The actual account is as straightforward as can be: Describe the target system in type theory or through a diagram, infer any first-order sentence (in the same vocabulary) that is consistent with the description, and then interpret that sentence, possibly differently than in the description of the target system.

Note the gain from phrasing the immersion-inference-interpretation account syntactically: For one, it becomes clear how this account relates to the standard account of inference known from the philosophy of language and used in the Received View (e. g. Carnap 1939, $\$ \iint_{23-24}$ ). The standard account consists of the description of the system in a language with a fixed interpretation, the inference of conclusions entailed by that description, and the interpretation of those conclusions. French's account deviates in two ways: First, the inferential stage involves consistency rather than entailment; this is the result of choosing partial truth rather than truth. Second, the description of the target system can be interpreted differently than the conclusions.

Another gain achieved from the syntactic formulation is a deeper analysis of the two deviant features. The first feature amounts to a change of the question: Rather than enquiring what we can be certain about given the information we have about the target system, we are now enquiring what could be the case given the information we have about the target system. Thus, the standard account and French's account complement each other nicely. The second feature of French's account amounts to a reinterpretation of the meaning of the non-logical constants used in the description of the target system after the inference is drawn. This possible reinterpretation loses a lot of information (only information that is invariant under partial isomorphism is retained), unless the two partial isomorphisms restrict each other in some way. Formally, this second feature is described by Hempel $(1965,435-436)$ as a syntactic isomorphism, a bijection between the non-logical constants of a set of sentences (where constants are assumed to have a fixed interpretation). Hempel suggests that analogical models are governed by laws that are syntactically isomorphic to the laws of the target system. How this relates to the scientific representation of one and the same target system remains 
to be seen.

\section{On whether there are theories}

While French's account of representation is similar to that of the logical empiricists' Received View, French's discussion of the ontology of theories is utterly alien to the views of the logical empiricists, who (with the notable exception of Feigl [1950]) famously disavowed metaphysics and never tried to determine what a theory is (Lutz 2012b, \$5.2). Carnap (1950) in particular claimed that whether some theoretical, and in particular abstract, entity exists is determined by the conventional choice of the linguistic framework in which to discuss it existence. Thus, within a linguistic framework, one can answer the "internal" question whether theories exist by checking the framework's formal features and, if necessary, make empirical enquiries. But the "external" question about whether some linguistic framework is correct has no answer. One can only meaningfully ask whether the framework is expedient for the task at hand (cf. Lutz 2012a, 190). Hence the logical empiricist answer to the external question "What are theories?" (49) is not that "a theory is the logico-linguistic entity $T C$ " (4), where $T C$ is the axiomatization of the theory. It is: "Whatever you choose for your linguistic framework."

French $(186-188,219-223)$ dissolves the problem of the essence of theories in a different way: The problem of how theories, understood as abstract objects, can be created when abstract objects cannot, and the difficulty of finding a universally accepted criterion of identity for theories let him conclude that there are no theories. To account for our talk of theories, French follows Ross Cameron in distinguishing between two languages: Ontologese, in which statements about $x$ can only be made true by $x$, and ordinary English, in which statements about $x$ can be made true by $x$ or something else. In Ontologese, the statement 'Newtonian mechanics is indeterministic' is not true because Newtonian mechanics does not exist. In ordinary English, 'Newtonian mechanics is indeterministic' is made true by the practices of scientists and philosophers of science (189-193, 236-239).

Carnap (1950) would be happy with the two languages, that is, the two linguistic frameworks. He would disagree, of course, with the view that only Ontologese describes what the world is really like. And that would be reasonable, because French's arguments for Ontologese (against the existence of theories) already rely on ontological assumptions: The first argument assumes, for instance, that the extension of 'is the same theory as' is to be invariant across contexts, and the second argument assumes that abstract objects are not created. Both assumptions can be jettisoned by changing the linguistic framework: ' $x$ is the same theory as $y$ ' can be replaced by 'theory $x$ is equivalent to theory $y$ in context $z$ ' (cf. Douven and Decock 2010) and one can assume that abstract objects can be created, as long as one changes the rest of the linguistic framework so that it stays consistent and empirically adequate. It seems that since French accepts a revisionary ontology regarding theories because of prior commitments regard- 
ing abstract objects, he could just as well accept a revisionary ontology regarding abstract objects because of prior commitments regarding theories.

\section{Rapprochement}

So we end up with a Partial Structures View whose formalism can be in principle and in practice be wholly expressed in the formalism of the Received View, and whose application to inferences about target systems is, but for one unexplained oddity, complementary to the application of the Received View. French's view further allows the possibility of speaking as a realist and as an antirealist about theories, just as Carnap assumes, and only disagrees with the logical empiricists, or at least Carnap, in assuming that the only ontologically correct language is the one according to which theories do not, and theoretical entities do exist. Once French views this assumption as a choice, it will be my pleasure to welcome him to the fold of logical empiricism.

\section{Acknowledgments}

I thank Neil Dewar and Nick Wiltsher for discussions.

\section{References}

Andrews, Peter B. 2002. An Introduction to Mathematical Logic and Type Theory: To Truth Through Proof. 2nd ed. Applied Logic Series 27. Dordrecht: Kluwer Academic Publishers. https://doi.org/10.1007/978-94-015-9934-4.

Bueno, Otávio. 2000. "Empiricism, Scientific Change and Mathematical Change." Studies in the History and Philosophy of Science 31 (2): 269-296. https://doi.org/10.1016/So039-3681(99)00037-0.

Carnap, Rudolf. 1939. Foundations of Logic and Mathematics. I:139-213. Foundations of the Unity of Science. Toward an International Encyclopedia of Unified Science. Chicago and London: University of Chicago Press. References are to the two-volume edition.

1950. "Empiricism, Semantics, and Ontology." Revue Internationale de Philosophie 4:20-40. References are to the slightly modified reprint (Carnap 1956, appendix A).

1956. Meaning and Necessity. 2nd ed. Chicago: University of Chicago Press.

Da Costa, Newton C. A., and Rolando Chuaqui. 1988. "On Suppes' Set Theoretical Predicates." Erkenntnis 29 (1): 95-112. https://doi.org/10.1007/ BFoo166367. 
Douven, Igor, and Lieven Decock. 2010. "Identity and Similarity." Philosophical Studies 151:59-78. https://doi.org/10.1007/s11098-009-9415-5.

Feigl, Herbert. 1950. "Existential Hypotheses: Realistic Versus Phenomenalistic Interpretations." Philosophy of Science 17:35-62. https://doi.org/10.1086/ 287065 .

French, Steven. 2020. There Are No Such Things as Theories. Oxford: Oxford University Press.

French, Steven, and James Ladyman. 1999. "Reinflating the Semantic Approach." International Studies in the Philosophy of Science 13 (2): 103-121. https://doi. org/10.1080/02698599908573612.

Halvorson, Hans. 2013. “The Semantic View, if Plausible, is Syntactic.” Philosophy of Science 80 (3): 475-478. https://doi.org/10.1086/671077.

Hempel, Carl G. 1965. "Aspects of Scientific Explanation.” In Aspects of Scientific Explanation and Other Essays in the Philosophy of Science, 331-496. New York: The Free Press.

Hudetz, Laurenz. 2017. "The Semantic View of Theories and Higher-Order Languages." Synthese 196:1131-1149. https://doi.org/10.1007/s11229-017-1502-0.

Lutz, Sebastian. 2012a. "Artificial Language Philosophy of Science." European Journal for Philosophy of Science 2 (2): 181-203. https://doi.org/10.1007/ s13194-011-0042-6.

2012b. "On a Straw Man in the Philosophy of Science: A Defense of the Received View." HOPOS: The Journal of the International Society for the History of Philosophy of Science 2 (1): 77-120. https://doi.org/10.1086/6644 60.

2014. "What's Right With a Syntactic Approach to Theories and Models?” Erkenntnis 79 (Suppl. 8): 1475-1492. https://doi.org/10.1007/s10670013-9578-5.

2015. "Partial Model Theory as Model Theory." Ergo 2 (22): 563-580. https://doi.org/10.3998/ergo.12405314.0002.022.

—. 2019. "Generalizing Empirical Adequacy II: Partial Structures." Forthcoming, Synthese, https://doi.org/10.1007/s11229-019-02121-z.

Mermin, N. David. 1993. "Hidden Variables and the two Theorems of John Bell." Reviews of Modern Physics 65 (3): 803-815.

Mikenberg, Irene, Newton C. A. da Costa, and Rolando Chuaqui. 1986. "Pragmatic Truth and Approximation to Truth.” The Journal of Symbolic Logic 51 (1): 201-221. https://doi.org/10.2307/2273956. 
Sarkar, Sahotra. 1992. “The Boundless Ocean of Unlimited Possibilities': Logic in Carnap's 'Logical Syntax of Language.'” Synthese 93 (1/2): 191-237.

Thomson-Jones, Martin. 2006. "Models and the Semantic View." Philosophy of Science 73:524-535. 